\title{
The safety of upper gastrointestinal endoscopic biopsy in patients receiving antithrombic drugs. A single-centre prospective observational study
}

\author{
Hilmi Bozkurt ${ }^{1}$, Tolga Ölmez ${ }^{1}$, Can İbrahim Bulut ${ }^{1}$, Özlem Zeliha Sert ${ }^{1}$, Zeynep Zehra Keklikkıran ${ }^{1}$, \\ Erdal Karaköse ${ }^{1}$, Aziz Serkan Senger ${ }^{1}$, Sabiye Akbulut ${ }^{2}$, Erdal Polat ${ }^{1}$, Mustafa Duman ${ }^{1}$ \\ ${ }^{1}$ Gastrointestinal Surgery Department, Kartal Koşuyolu Training and Research Hospital, Istanbul, Turkey \\ ${ }^{2}$ Gastroenterology Department, Kartal Koşuyolu Training and Research Hospital, Istanbul, Turkey
}

Gastroenterology Rev 2020; 15 (3): 234-240

DOI: https://doi.org/10.5114/pg.2019.88622

Key words: antithrombotic, endoscopic biopsy, bleeding.

Address for correspondence: Hilmi Bozkurt MD, Gastrointestinal Surgery Department, Kartal Koşuyolu Training and Research Hospital, 34865 Istanbul, Turkey, phone: +905321780880, e-mail: hilmibozkurt27@gmail.com

\begin{abstract}
Introduction: In July 2012, the Japan Gastroenterological Endoscopy Society updated their guidelines on gastroenterological endoscopy in patients undergoing antithrombotic therapy, although the safety of endoscopic procedures in patients receiving antithrombotic drugs has yet to be sufficiently studied.

Aim: This study evaluates the safety of upper gastroenterological endoscopic biopsy in patients receiving antithrombotic drugs. We evaluated the prospective observational safety of endoscopic biopsy performed in the endoscopy unit of our patients using antithrombotic drugs.

Material and methods: Oesophagogastroduodenoscopies (OGD) and biopsies performed at a single endoscopy unit between July 2018 and February 2019 were examined in this prospective observational study. Patients receiving antithrombotic drugs due to cardiovascular and neurological reasons, who underwent an endoscopic mucosal biopsy for diagnostic purposes, were included in the study.

Results: The study was completed with 166 patients who underwent an endoscopic biopsy, from whom a total of 327 biopsies taken. The patients were examined in two groups: those "receiving antithrombotic drugs" and those who had "stopped taking antithrombotic drugs". There was no statistically significant difference between the two groups with respect to bleeding.

Conclusions: This prospective observational study showed that performing an endoscopic biopsy without the cessation of antithrombotic drugs does not increase bleeding risk. Low-risk procedures, such as endoscopic mucosal biopsies, can be performed confidently by experienced endoscopists.
\end{abstract}

\section{Introduction}

Antithrombotics, consisting of antiplatelets and anticoagulants, are generally used to prevent cardiovascular and cerebrovascular events [1-3]. Antiplatelet agents are widely used around the world for the prevention of atherothrombotic diseases, including myocardial infarction, ischaemic stroke, and occlusive peripheral arterial disease [4]. Low-dose aspirin is widely used for the primary and secondary prevention of cardiovascular events. Thienopyridine derivatives such as ticlopidine and clopidogrel are mandatory after coronary stent placement until endothelialisation is complete. Dual-antiplatelet therapy with an aspirin and clopidogrel combi- nation is required for 3 months for metal stents, and for up to 1 year for drug-eluting stents [5-7]. Warfarin and direct oral anticoagulant (DOAC) drugs are administered for other clinical conditions, such as atrial fibrillation, valve replacement, stroke, and the prevention of recurrent venous thromboembolism [8, 9].
Aim
Even though the usage of antithrombotic agents con- tributes to the prevention of a variety of vascular diseas- es, patients being treated with these drugs carry a risk of gastrointestinal (GI) bleeding [10, 11]. For this reason, endoscopic diagnosis and treatment procedures must be performed taking bleeding risk into consideration. 
It is thought that the cessation of antithrombotic drugs prior to endoscopic examination decreases Gl bleeding risk [12-14], although thrombosis caused by cessation is closely related to such major complications as a higher mortality rate $[15,16]$. The Japan Gastroenterological Endoscopy Society (JGES) issued a new guideline in 2012 for the management of anticoagulant and antiplatelet agents for endoscopic procedures [17]. According to this guideline, avoiding thromboembolic complications is much more important than avoiding bleeding, and it is not recommended to cease antithrombotic usage before such minimally invasive procedures as biopsies in a gastrointestinal tract endoscopy $[17,18]$. The safety of upper gastrointestinal endoscopic biopsy procedures in patients using antithrombotics is evaluated in this prospective observational study, according to the JGES 2012 guideline.

\section{Material and methods}

Oesophagogastroduodenoscopies (OGD) and biopsies performed at a single endoscopy unit between July 2018 and February 2019 were examined in this prospective observational study. Patients receiving antithrombotic drugs for cardiovascular and neurological reasons, who were subjected to endoscopic mucosal biopsies for diagnostic purposes, were included in the study. Constitutively, endoscopic mucosal biopsy procedures for diagnostic reasons such as malignancy suspicion and scanning, anaemia aetiology, functional dyspepsia, and Helicobacter pylori were included. A limited number of biopsies were taken in the group with high risk of bleeding. Those undergoing therapeutic procedures such as haemostatic operations for the emergency treatment of GI bleeding, polypectomy, endoscopic mucosal resection (EMR), and endoscopic submucosal dissection (ESD) were excluded from the study.

The cessation of antithrombotic drugs in advance of an endoscopic procedure, switching to bridging therapy, or continuation of the drugs during the procedure was decided upon by the cardiologists, cardiovascular surgeons, or neurologists who prescribed the drugs. Ultimately, the patients who approved of the procedure were included in the study. In this study the anticoagulants taken as antithrombotic agents to evaluate the bleeding risk were warfarin, rivaroxaban, and apixaban, and antiplatelets aspirin (100 mg) and clopidogrel. No biopsies were taken from the patients using warfarin if the international normalised ratio international normalized ratio (INR) was higher than 3.0 , because the bleeding risk is significantly higher in such patients. If the INR value was between 2.0 and 3.0, the procedure was carried out after reducing the INR to below 2.0, after consulting the related doctor about the cessation of warfarin or switching to bridging therapy.
The biopsies were performed by the gastroenterologists and gastroenterological surgeons of a single centre, and only on patients with endoscopic findings that required a pathological evaluation. A Fujinon VP-4450HD/XL-4450 Video Endoscopy System (Fujinon Japan) and an Olympus Evis Exera CV-160 Video Endoscopy System (Olympus, Japan) were used. All biopsies were taken with Micro-Tech Biopsy Forceps (Nanjing/ China) Co. Ltd (2.3 mm). Coagulation catheters (Olympus, Japan) were used. Minor bleeding was defined as blood leakage that required endoscopic haemostasis during the procedure, and major bleeding was determined as apparent haematemesis, melena or a fall in haemoglobin $(\mathrm{Hb})$ levels of more than $2 \mathrm{~g} / \mathrm{dl}$, or a blood transfusion requirement [19]. Bleeding was stopped by using electrocautery during the procedure. Findings were noted from before, during, and after the endoscopy procedure.

Patients were advised to contact our institution in the event of haematemesis or melena after the biopsy, and those who returned were hospitalised and subjected to a control endoscopy after clinical confirmation of bleeding. The patients were summoned for control physical examinations 4 weeks after the biopsy, and those who did not apply were contacted by telephone in case they had applied to other hospitals with bleeding. Patients showing any symptoms were checked with blood tests.

Ethical approval for the study was obtained from the our hospital Ethics Committee: Approval no: 2018.4/296; approval date: 25.05.2018.

\section{Statistical analysis}

Mean, standard deviation, median, minimum, maximum, frequency, and ratio values were used in the descriptive statistics of the data. The distribution of the variants was measured with a Kolmogorov-Smirnov test. Unpaired quantitative data were analysed using unpaired $t$ test, Mann-Whitney $U$ test. Unpaired qualitative data were analysed using Ki-kare test, and the Fisher test was used when requirements were not met for the Ki-kare test. SPSS 22.0 software was used for the analyses.

\section{Results}

A total of 288 patients using antithrombotics, who underwent an upper gastrointestinal endoscopy, were included in the study. Of these, seven had an endoscopy under emergency conditions, 17 patients were subjected to a polypectomy and EMR, 77 patients had no biopsies taken during the procedures, and 21 patients were lost to follow-up, and thus were excluded from the study (Figure 1). The study was completed with 166 patients 


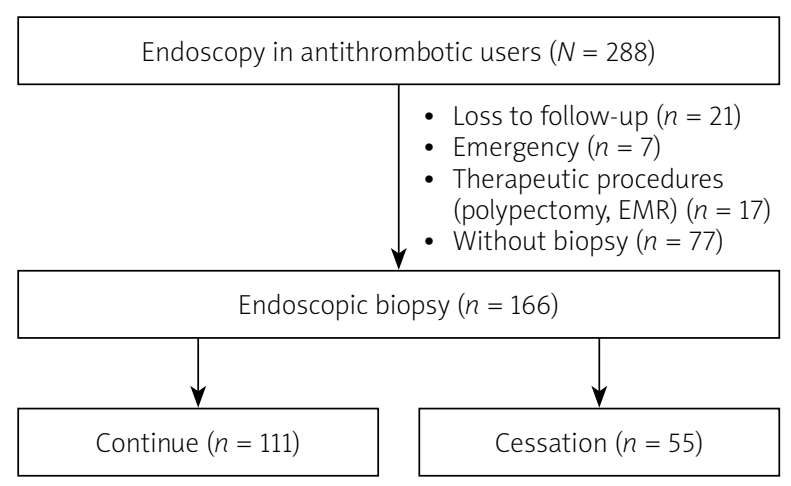

Figure 1. Flow diagram of the study (30-day follow-up and analysis)

who underwent an endoscopic biopsy, with a total of 327 biopsies taken from these patients. The general and demographic data of these patients are presented in Table I. Following the recommendations of the doctors who prescribed the antithrombotic drugs, an endoscopic biopsy was performed in 111 patients without cessation of drugs and in 55 patients with cessation of drugs. Bridging therapy was applied to 20 of the 55 patients in the cessation group. There was no statistically significant difference $(p>0.05)$ in the age or sex distribution of the patients between the two groups "receiving antithrombotic drugs" and those who "stopped taking antithrombotic drugs". There was no statistically significant difference $(p>0.05)$ in the antithrombotic usage rates of the two groups, and there was no statistically significant difference $(p>0.05)$ in the PPI usage ratios of the two groups. There was no statistically significant difference $(p>0.05)$ in bleeding rates after the procedure between the two groups (Table II).

Furthermore, there was no statistically significant difference $(p>0.05)$ in the age and sex distribution of the patients between the two groups "using PPI" and "not using PPI", and there was no statistically significant difference in antithrombotic usage ratio between the same two groups $(p>0.05)$. There was no statistically significant difference in the low molecular weight heparin $(\mathrm{LMWH})$ ratio between the two groups "using PPI" and "not using PPI" ( $p>0.05)$, and there was no statistically significant difference in bleeding rates following the procedure between the same two groups $(p>0.05)$ (Table III). There were 2 cases of bleeding - one minor and one major (Table IV). No thromboembolism was seen in the group in which antithrombotic drugs were discontinued.

\section{Discussion}

In this single-centre prospective observational study we investigated the bleeding risk after upper gastrointestinal endoscopic mucosal biopsy procedures in
Table I. Demographic data

\begin{tabular}{|c|c|c|c|}
\hline Parameter & Min.-max. & Median & $\begin{array}{c}\text { Mean } \pm \text { SD } \\
\text { or } n(\%)\end{array}$ \\
\hline Age & $34.0-86.0$ & 61.0 & $61.0 \pm 9.5$ \\
\hline \multicolumn{4}{|l|}{ Gender: } \\
\hline Female & & & $84(50.6)$ \\
\hline Male & & & $82(49.4)$ \\
\hline \multicolumn{4}{|l|}{ Disease: } \\
\hline $\begin{array}{l}\text { Coronary artery } \\
\text { disease }\end{array}$ & & & $84(50.6)$ \\
\hline $\begin{array}{l}\text { Mitral valve } \\
\text { replacement }\end{array}$ & & & $17(10.2)$ \\
\hline Cardiac stents & & & $28(16.9)$ \\
\hline Coronary bypass & & & $10(6.0)$ \\
\hline Cardiac insufficiency & & & $9(5.4)$ \\
\hline Atrial fibrillation & & & $12(7.2)$ \\
\hline $\begin{array}{l}\text { Cerebrovascular } \\
\text { disease }\end{array}$ & & & $6(3.6)$ \\
\hline \multicolumn{4}{|l|}{ Antithrombotic: } \\
\hline Apixaban & & & $2(1.2)$ \\
\hline \multicolumn{4}{|l|}{ Aspirin (100 mg/day) } \\
\hline Warfarin & & & $23(13.9)$ \\
\hline Warfarin + aspirin & & & $2(1.2)$ \\
\hline Clopidogrel & & & $15(9.0)$ \\
\hline Clopidogrel + aspirin & & & $6(3.6)$ \\
\hline Rivaroxaban & & & $7(4.2)$ \\
\hline \multicolumn{4}{|l|}{ Antithrombotic: } \\
\hline Single & & & $158(95.2)$ \\
\hline Multiple & & & $8(4.8)$ \\
\hline \multicolumn{4}{|l|}{ Indication: } \\
\hline Anaemia & & & 29 (17.5) \\
\hline Dyspepsia & & & $50(30.1)$ \\
\hline Malignancy screening & & & $87(52.4)$ \\
\hline \multicolumn{4}{|l|}{ LMWH bridging: } \\
\hline No & & & $146(88.0)$ \\
\hline Yes & & & $20(12.0)$ \\
\hline \multicolumn{4}{|l|}{ PPI: } \\
\hline No user & & & $75(45.2)$ \\
\hline User & & & $91(54.8)$ \\
\hline \multicolumn{4}{|l|}{ Bleeding: } \\
\hline No bleeding & & & $164(98.8)$ \\
\hline Minor bleeding & & & $1(0.6)$ \\
\hline Major bleeding & & & $1(0.6)$ \\
\hline INR (only warfarin user) & 0.89-1.91 & 0.00 & $1.37 \pm 0.24$ \\
\hline
\end{tabular}

LMWH - low molecular weight heparin, PPI - proton pump inhibitor,

INR - international normalised ratio, Min. - minimum, Max. - maximum. 
Table II. Groups that discontinued and continued the drug during biopsy

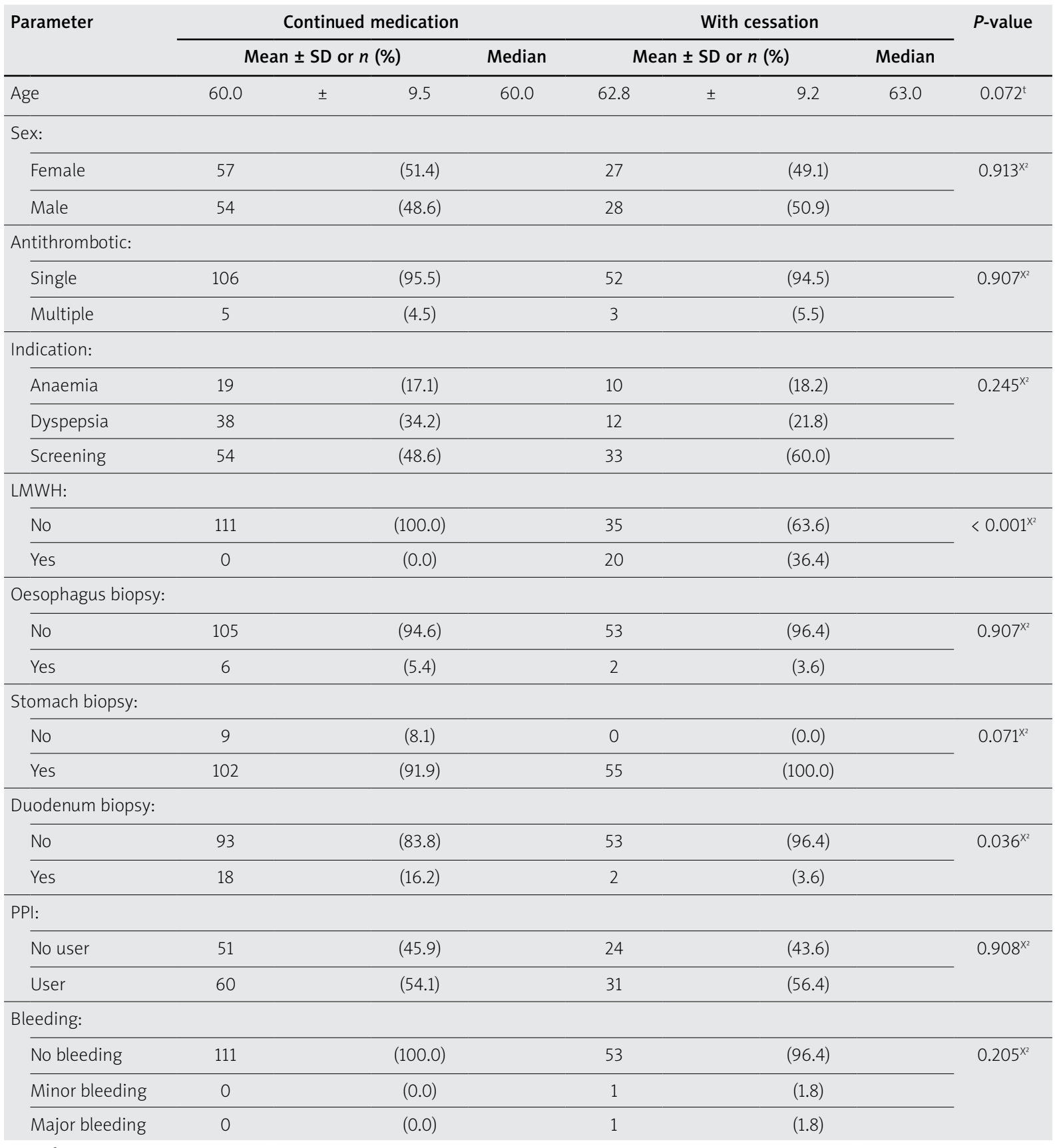

${ }^{t} t$ test $/{ }^{2} \mathrm{Ki}$-kare test, $L M W H$ - low molecular weight heparin, PPI - proton pump inhibitor, Min. - minimum, Max. - maximum

patients using antithrombotic agents, who continued taking their drugs and in those who had stopped (control group) during the procedure. The findings of the study revealed that performing an endoscopic mucosal biopsy without the cessation of antithrombotics does not increase the risk of bleeding either during or within the first 30 days following the procedure.

Thromboembolisms may have more serious consequences than bleeding in patients ceasing antithrom- botic therapy for an endoscopic biopsy $[12,13]$. Previous studies have provided only limited data on the safety of endoscopic mucosal biopsies in patients taking antithrombotics. Fujita et al. [20] reported a bleeding incidence after a biopsy without cessation of antithrombotic treatment of $1.5 \%$. Ara et al. [15] identified a bleeding incidence after biopsy in patients continuing antithrombotics of $0.35 \%$. Similarly, Mabe et al. [21] and Kono et al. [19] reported in their studies that 
Table III. Groups using and not using PPIs

\begin{tabular}{|c|c|c|c|c|c|c|c|c|}
\hline \multirow{3}{*}{$\begin{array}{l}\text { Parameter } \\
\text { Age }\end{array}$} & \multicolumn{7}{|c|}{ PPI user } & \multirow{3}{*}{$\frac{P \text {-value }}{0.602^{t}}$} \\
\hline & \multicolumn{3}{|c|}{ Mean \pm SD or $n(\%)$} & \multicolumn{3}{|c|}{ Mean \pm SD or $n(\%)$} & \multirow{2}{*}{$\frac{\text { Median }}{61.0}$} & \\
\hline & 60.5 & \pm & 8.5 & 61.3 & \pm & 10.2 & & \\
\hline \multicolumn{9}{|l|}{ Gender: } \\
\hline Female & 33 & & $(44.0)$ & 51 & & $(56.0)$ & & \multirow[t]{2}{*}{$0.164^{x^{2}}$} \\
\hline Male & 42 & & $(56.0)$ & 40 & & $(44.0)$ & & \\
\hline \multicolumn{9}{|l|}{ Antithrombotic: } \\
\hline Single & 72 & & $(96.0)$ & 86 & & $(94.5)$ & & \multirow[t]{2}{*}{$0.933^{x^{2}}$} \\
\hline Multiple & 3 & & $(4.0)$ & 5 & & $(5.5)$ & & \\
\hline \multicolumn{9}{|l|}{ Indication: } \\
\hline Anaemia & 12 & & $(16.0)$ & 17 & & $(18.7)$ & & \multirow[t]{3}{*}{$0.040^{x^{2}}$} \\
\hline Dyspepsia & 16 & & $(21.3)$ & 34 & & (37.4) & & \\
\hline Malignancy screening & 47 & & $(62.7)$ & 40 & & $(44.0)$ & & \\
\hline \multicolumn{9}{|l|}{ LMWH: } \\
\hline No & 67 & & $(89.3)$ & 79 & & $(86.8)$ & & \multirow[t]{2}{*}{$0.797^{x^{2}}$} \\
\hline Yes & 8 & & $(10.7)$ & 12 & & $(13.2)$ & & \\
\hline \multicolumn{9}{|l|}{ Oesophagus biopsy: } \\
\hline No & 73 & & $(97.3)$ & 85 & & (93.4) & & \multirow[t]{2}{*}{$0.417^{x^{2}}$} \\
\hline Yes & 2 & & $(2.7)$ & 6 & & (6.6) & & \\
\hline \multicolumn{9}{|l|}{ Stomach biopsy: } \\
\hline No & 4 & & $(5.3)$ & 5 & & $(5.5)$ & & \multirow[t]{2}{*}{$0.765^{x^{2}}$} \\
\hline Yes & 71 & & $(94.7)$ & 86 & & $(94.5)$ & & \\
\hline \multicolumn{9}{|l|}{ Duodenum biopsy: } \\
\hline No & 65 & & $(86.7)$ & 81 & & (89.0) & & \multirow[t]{2}{*}{$0.824^{x^{2}}$} \\
\hline Yes & 10 & & (13.3) & 10 & & $(11.0)$ & & \\
\hline \multicolumn{9}{|l|}{ Bleeding: } \\
\hline No bleeding & 75 & & (100.0) & 89 & & $(97.8)$ & & \multirow[t]{3}{*}{$0.564^{x^{2}}$} \\
\hline Minor bleeding & 0 & & $(0.0)$ & 1 & & (1.1) & & \\
\hline Major bleeding & 0 & & $(0.0)$ & 1 & & (1.1) & & \\
\hline
\end{tabular}

Table IV. Bleeding patients

\begin{tabular}{lcccccccc} 
Gender/age & Drug & $\begin{array}{c}\text { Coexistig } \\
\text { disease }\end{array}$ & Biopsy & Biopsy no. & Indication & Treatment & $\begin{array}{c}\text { With } \\
\text { cessation }\end{array}$ \\
\hline Female/53 & Aspirin & $\begin{array}{c}\text { Coronary } \\
\text { by-pass }\end{array}$ & $\begin{array}{c}\text { Gastric } \\
\text { antrum }\end{array}$ & 2 & $\begin{array}{c}\text { Malignancy } \\
\text { screening }\end{array}$ & $\begin{array}{c}\text { ES replacement, } \\
\text { electrocoagulation }\end{array}$ & $\begin{array}{c}3 \text { days } \\
\text { (no-bridging) }\end{array}$ & $\begin{array}{c}\text { Yes } \\
\text { Male/73 }\end{array}$ \\
\hline $\begin{array}{l}\text { Warfarin } \\
\text { (INR: } 1 / .32)\end{array}$ & $\begin{array}{c}\text { Atrial } \\
\text { fibrillation }\end{array}$ & $\begin{array}{c}\text { Gastric } \\
\text { antrum }\end{array}$ & 2 & Dyspepsia & electrocoagulation & 5 days & No \\
(no-bridging)
\end{tabular}

ES - erythrocyte suspension, PPI - proton pump inhibitor.

bleeding in patients receiving antithrombotic therapy was $0.76-1.0 \%$. The bleeding rate in patients undergoing antithrombotic therapy was found to be $1.2 \%$ in the present study. One surprising finding of the present study is that the two patients with bleeding symptoms were in the group that stopped taking antithrombotic drugs. In line with the recommendations made in the available guidelines, we suggest that an endoscopic mucosal biopsy may be performed safely in patients taking antithrombotics. 
While there have been some studies showing that a standard dose of aspirin alone does not increase the bleeding rate after an endoscopic biopsy, there have been a limited number of prospective studies properly evaluating the safety of antithrombotic therapy in patients undergoing an OGD biopsy [15, 18, 22]. According to new JGES guidelines, aspirin, non-aspirin antiplatelets, or anticoagulants need not be ceased for an endoscopic mucosal biopsy [16], although drug cessation decisions for patients undertaking dual or triple antithrombotic therapies should be considered on a case-by-case basis [17, 23]. Ono et al. [18] investigated the difference in endoscopic bleeding time of 60 patients taking antithrombotic drugs and found no statistically significant difference between the patients taking single or multiple antithrombotic drugs ( $2.4 \pm 1.4 \mathrm{~min}$ vs. $2.1 \pm 2.1 \mathrm{~min})$. In contrast, Kono et al. [19] identified an increased bleeding risk in patients undergoing multiple antithrombotic therapy, even after the cessation of all drugs before the biopsy. In the present study, no bleeding was noted in the group that continued taking drugs, aspirin being the most common antithrombotic ( $n=111,66.9 \%)$, while there was one case of bleeding in the group that stopped taking drugs. No bleeding was observed in 8 cases $(4.8 \%)$ on multiple (dual) antithrombotic therapies. Based on these results, we conclude that that such procedures can be performed confidently in patients with single antiplatelet usage, but, despite no bleeding being noted in patients on dual drug therapy in our study, we suggest they be handled on a case-bycase basis and with precaution, due to the low number of cases.

Warfarin, which is an anticoagulant drug, is widely used for prevention of thrombosis and thromboembolism. The JGES guidelines recommend the continuation of warfarin in patients with PT-INR levels between the therapeutic ranges [17]. In western countries, the recommended target level for PT-INR levels is between 2.0 and 3.0 [24, 25]. Yuki et al. [26] found in their prospective observational study that bleeding risk did not increase due to anticoagulant usage. The previously recorded mean PT-INR levels of Japanese patients using warfarin were $1.99 \pm 0.24$ [27]. Fujita et al. [20] similarly reported a mean PT-INR level of $1.77 \pm 0.67$ in their retrospective observational study. In the present study the mean PT-INR level of patients using warfarin was found to be $1.37 \pm 0.24$. In line with the recommendations of the JGES guidelines, patients using warfarin must be considered primarily as high-risk cases [19]. In fact, in the present study, bleeding was noted in a case with an INR level of 1.32 in the "stopped taking antithrombotic drugs" group.
There is only limited information in the literature about PPI usage among patients taking antithrombotics during biopsy. Ara et al. [15] showed in their prospective study that bleeding risk is not decreased by PPI usage. Similarly, no statistically significant difference was found between the two groups "using PPI" and "not using PPI" in this study.

The limitations of the study were its single-centre design, its failure to include invasive and high-risk procedures such as polypectomy and EMR, and the low ratio of usage of new antithrombotic drugs, primarily direct oral anticoagulants, in the study.

\section{Conclusions}

This prospective observational study has shown that performing an endoscopic biopsy without cessation of antithrombotic drugs does not increase bleeding risk. Low-risk procedures such as endoscopic mucosal biopsies can be performed confidently by experienced endoscopists. Large-scale studies are needed to evaluate the effects on bleeding risk of procedures with higher risks and use of newly available antithrombotics.

\section{Conflict of interest}

The authors declare no conflict of interest.

\section{References}

1. Yasue H, Ogawa H, Tanaka H, et al. Effects of aspirin and trapidil on cardiovascular events after acute myocardial infarction. Japanese Antiplatelets Myocardial Infarction Study (JAMIS) Investigators. Am J Cardiol 1999; 83: 1308-13.

2. De Caterina R, Husted S, Wallentin L, et al. New oral anticoagulants in atrial fibrillation and acute coronary syndromes: ESC Working Group on Thrombosis-Task Force on Anticoagulants in Heart Disease position paper. J Am Coll Cardiol 2012; 59: 1413-25.

3. Yusuf S, Zhao F, Mehta SR, et al. Effects of clopidogrel in addition to aspirin in patients with acute coronary syndromes without ST-segment elevation. N Engl J Med 2001; 345: 494502.

4. Lansberg MG, O'Donnell MJ, Khatri P, et al. Antithrombotic and thrombolytic therapy for ischemic stroke: Antithrombotic Therapy and Prevention of Thrombosis, 9th ed: American College of Chest Physicians Evidence-Based Clinical Practice Guidelines. Chest 2012; 141: e601S-36S.

5. Brighton TA, Eikelboom JW, Mann K, et al. Low-dose aspirin for preventing recurrent venous thromboembolism. N Engl J Med 2012; 367: 1979-87.

6. Okada S, Morimoto T, Ogawa H, et al. Effect of low-dose aspirin on primary prevention of cardiovascular events in Japanese diabetic patients at high risk. Circ J 2013; 77: 3023-8.

7. Cooke GE, Goldschmidt-Clermont PJ, et al. The safety and efficacy of aspirin and clopidogrel as a combination treatment in patients with coronary heart disease. Expert Opin Drug Saf 2006; 5: 815-26. 
8. Xiong Q, Lau YC, Senoo K, et al. Non-vitamin K antagonist oral anticoagulants (NOACs) in patients with concomitant atrial fibrillation and heart failure: a systemic review and meta-analysis of randomized trials. Eur J Heart Fail 2015; 17: 1192-200.

9. Rubboli A, Agewall S, Huber K, et al. New-onset atrial fibrillation after recent coronary stenting: warfarin or non-vitamin $\mathrm{K}$-antagonist oral anticoagulants to be added to aspirin and clopidogrel? A view point. Int J Cardiol 2015; 196: 133-8.

10. Sorensen HT, Mellemkjaer L, Blot WJ, et al. Risk of upper gastrointestinal bleeding associated with use of low- dose aspirin. Am J Gastroenterol 2000; 95: 2218-24.

11. Hallas J, Dall M, Andries A, et al. Use of single and combined antithrombotic therapy and risk of serious upper gastrointestinal bleeding: population based case-control study. BMJ 2006; 333: 726.

12. Bhatt DL, Scheiman J, Abraham NS, et al. American College of Cardiology Foundation American College of Gastroenterology American Heart Association. ACCF/ACG/AHA 2008 expert consensus document on reducing the Gastrointestinal risks of antiplatelet the therapy and NSAID use: a report of the American College of Cardiology Foundation Task Force on Clinical Expert Consensus Documents. Circulation 2008; 118: 1894-909.

13. Becker RC, Scheiman J, Dauerman HL, et al.; American College of Cardiology and the American College of Gastroenterology. Management of platelet-directed pharmacotherapy in patients with atherosclerotic coronary artery disease under- going elective endoscopic gastrointestinal procedures. J Am Coll Cardiol 2009; 54: 2261-76.

14. Wijeysundera DN, Wijeysundera HC, Yun L, et al. Risk of elective major noncardiac surgery after coronary stent insertion: a population-based study. Circulation 2012; 126: 1355-62.

15. Ara N, lijima K, Maejima R, et al. Prospective analysis of risk for bleeding after endoscopic biopsy without cessation of antithrombotics in Japan. Dig Endosc 2015; 27: 458-64.

16. Veitch AM, Vanbiervliet G, Gershlick AH, et al. Endoscopy in patients on antiplatelet or anticoagulant therapy, including direct oral anticoagulants: British Society of Gastroenterology (BSG) and European Society of Gastrointestinal Endoscopy (ESGE) guidelines. Gut 2016; 65: 374-89.

17. Fujimoto K, Fujishiro M, Katou M, et al. The management of anticoagulation and antiplatelet therapy for endoscopic procedures. Gastroenterol Endosc 2012; 54: 2075-102.

18. Ono S, Fujishiro M, Kodashima S, et al. Evaluation of safety of endoscopic biopsy without cessation of antithrombotic agents in Japan. J Gastroenterol 2012; 47: 770-4.

19. Kono Y, Matsubara M, Toyokawa T, et al. Multicenter prospective study on the safety of upper gastrointestinal endoscopic procedures in antithrombotic drug users. Dig Dis Sci 2017; 62: 730-8.

20. Fujita M, Shiotani A, Murao T, et al. Safety of gastrointestinal endoscopic biopsy in patients taking antithrombotics. Dig Endosc 2015; 27: 25-9.

21. Mabe K, Kato M, Oba K, et al. A prospective, multicenter survey on the validity of shorter periendoscopic cessation of antithrombotic agents in Japan. J Gastroenterol 2017; 52: 50-60.

22. Whitson MJ, Dikman AE, vonAlthann C, et al. Is gastroduodenal biopsy safe in patients receiving aspirin and clopidogrel a prospective, randomized study in volving 630 biopsies. J Clin Gastroenterol 2011; 45: 228-33.
23. Boustiere C, Veitch A, Vanbiervliet G, et al. Endoscopy and antiplatelet agents. European society of gastrointestinal endoscopy (ESGE) guideline. Endoscopy 2011; 43: 445-61.

24. Fuster V, Ryden LE, Cannom DS, et al. ACC/AHA/ESC 2006 Guidelines for the Management of Patients with Atrial Fibrillation: A report of the American College of Cardiology/American Heart Association Task Force on Practice Guidelines and the European Society of Cardiology Committee for Practice Guidelines (Writing Committee to Revise the 2001 Guidelines for the Management of Patients With Atrial Fibrillation): developed in collaboration with the European Heart Rhythm Association and the Heart Rhythm Society. Circulation 2006; 114: e257354.

25. Hart RG, Pearce LA, Aguilar MI. Meta-analysis: antithrombotic therapy to prevent stroke in patients who have nonvalvular atrial fibrillation. Ann InternMed 2007; 146: 857-67.

26. Yuki T, Ishihara S, Yashima K, et al. Bleeding risk related to upper gastrointestinal endoscopic biopsy in patients receiving antithrombotic therapy: a multicenter prospective observational study. Curr Ther Res Clin Exp 2017; 84: 32-6.

27. JCS Joint Working Group. Guidelines for pharmacotherapy of atrial fibrillation (JCS 2008): digest version. Circ J 2010; 74 : 2479-500.

Received: 21.08.2019

Accepted: 25.09.2019 